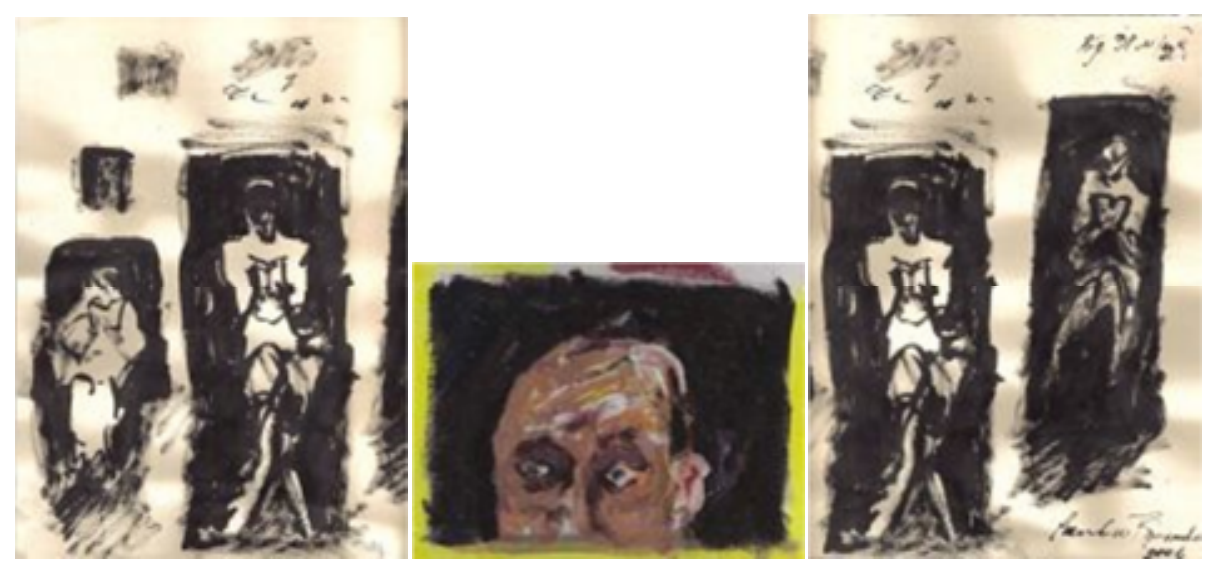

Ilustração Leandro Figueiredo

\title{
Por que eles não lêem? \\ refletindo sobre as implicações do não- desenvolvimento de habilidades de leitura (1)
}

\section{Cláudia Mara de Souza}

Mestre em Lingüistica pela FALE/UFMG. Professora da rede municipal de ensino de Itabira e da Fundação Comunitária de Ensino Superior de Itabira (FUNCESI).

\section{Resumo}

Este artigo tem o objetivo de apresentar uma reflexão sobre as principais habilidades de leitura verificadas em exame sistêmico e sobre as implicações do não-desenvolvimento de tais habilidades.

Palavras-chave: escola, habilidades de leitura e avaliação.

\section{Introdução}

Na escola evidencia-se uma grande contradição: os professores ensinam, alunos aprendem e, quando são submetidos a testes ou 
a provas, acontece o que muitos classificam como fracasso. Testes e provas mostram que os alunos não conseguem resolver as questões. Por exemplo, o relatório do Programa Internacional de Avaliação de Estudantes (PISA, 2000) mostra dificuldades para a maioria dos alunos brasileiros: construir uma resposta considerando informações de várias partes do texto; fazer inferências (as mais diversas); lidar com textos de gênero pouco familiar (não-contínuos, gráficos e tabelas, formulários). Será que os alunos realmente não desenvolveram aquelas habilidades de leitura? A escola tem realmente desenvolvido habilidades ou competências que levam o estudante a interagir com as operações mais complexas que alguns testes exigem?

Em sala de aula, os professores são freqüentemente interrogados pelos alunos sobre como resolver determinada questão ou exercício. É comum ter-se a impressão de que o aluno não lê os enunciados ou comandos das atividades, mesmo quando solicitados a reler o que dizem tais exercícios: parece que não compreendem o que fazer. Ouve-se, sempre, em salas de professores, a seguinte pergunta: "Por que eles não lêem?". Ouvem-se também algumas tentativas de respostas : "Os alunos não conseguem resolver os exercícios porque não compreendem os enunciados deles" ou "Porque não sabem ler".

Algumas perguntas surgem: Que habilidades os alunos brasileiros demonstram ter? Que implicações o nãodesenvolvimento das habilidades pode acarretar? Assim, este artigo apresenta uma breve reflexão sobre as habilidades de leitura avaliadas no Sistema Nacional de Avaliação da Educação Básica (SAEB) 2001 e sobre o resultado obtido pelos estudantes.

O desempenho dos alunos de $8^{a}$ série no SAEB

Muitos resultados de exames de proficiência têm sido divulgados pelos meios de comunicação. Esses resultados apontam para o fracasso da educação, se considerados os índices de acerto apresentados pela população estudantil brasileira em muitas das competências e habilidades avaliadas. Um destes exames é O SAEB e seus resultados são mostrados aqui, especificamente os do desempenho relacionados à leitura em Língua Portuguesa.

A tabela abaixo apresenta os resultados da oitava série do ensino fundamental, com a média geral alcançada pelos alunos brasileiros nas vinte e uma habilidades avaliadas. 
TABELA 1 - Média geral das habilidades avaliadas pelo SAEB $8^{a}$. Série

\begin{tabular}{|c|c|c|}
\hline $\begin{array}{c}N^{\circ} \\
\text { descritor }\end{array}$ & Habilidade descrita & $\begin{array}{c}\% \\
\text { (Porcentagem) }\end{array}$ \\
\hline D1 & Localizar informações explicitas em um texto. & 66,5 \\
\hline D2 & $\begin{array}{l}\text { Estabelecer relações entre partes de um texto, identificando } \\
\text { repetições ou substituições que contribuem para a continuidade de } \\
\text { um texto. }\end{array}$ & 45,3 \\
\hline D3 & Inferir o sentido de uma palavra. & 60,2 \\
\hline D4 & Inferir uma informação implicita em um texto. & 56,7 \\
\hline D5 & Desenvolver interpretação, integrando o texto e o material gráfico. & 52,1 \\
\hline D6 & Identificar o tema de um texto. & 55,2 \\
\hline D7 & Identificar a tese de um texto. & 44,5 \\
\hline D8 & $\begin{array}{l}\text { Estabelecer relação entre a tese e os argumentos oferecidos para } \\
\text { sustentá-la. }\end{array}$ & 65,3 \\
\hline D9 & Diferenciar as partes principais das secundárias de um texto. & 26,0 \\
\hline D10 & $\begin{array}{l}\text { Identificar o conflito gerador do enredo e os elementos que } \\
\text { constroem a narrativa. }\end{array}$ & 62,6 \\
\hline D11 & $\begin{array}{l}\text { Estabelecer relaçāo causa/consequeēncia entre partes e elementos } \\
\text { do texto. }\end{array}$ & 55,0 \\
\hline D12 & Identificar a finalidade de textos de diferentes gêneros. & 49,5 \\
\hline D13 & $\begin{array}{l}\text { Identificar as marcas lingüisticas que evidenciam o locutor e o } \\
\text { interlocutor de um texto. }\end{array}$ & 42,9 \\
\hline D14 & Distinguir um fato da opinião relativa a esse fato. & 53,5 \\
\hline D15 & $\begin{array}{l}\text { Estabelecer relações lógico-discursivas presentes no texto, } \\
\text { marcadas por conjunçōes, advérbios, etc. }\end{array}$ & 53,3 \\
\hline D16 & Perceber efeitos de ironia ou humor em textos variados. & 51,6 \\
\hline D17 & $\begin{array}{l}\text { Reconhecer o efeito de sentido decorrente do uso da pontuação e } \\
\text { de outras notaçőes. }\end{array}$ & 57,4 \\
\hline D18 & $\begin{array}{l}\text { Reconhecer o efeito de sentido decorrente da escolha de uma } \\
\text { determinada palavra ou expressão. }\end{array}$ & 60,8 \\
\hline D19 & $\begin{array}{l}\text { Reconhecer o efeito de sentido decorrente da exploração de } \\
\text { recursos ortográficos e/ou morfossintáticos. }\end{array}$ & 42,0 \\
\hline D20 & $\begin{array}{l}\text { Reconhecer diferentes formas de tratar uma informação na } \\
\text { comparação de textos que tratam do mesmo tema, em função das } \\
\text { condições em que eles foram produzidos e daquelas em que serão } \\
\text { recebidos. }\end{array}$ & 51,3 \\
\hline D21 & $\begin{array}{l}\text { Reconhecer posições distintas entre duas ou mais opiniões relativas } \\
\text { ao mesmo fato ou ao mesmo tema. }\end{array}$ & 45,0 \\
\hline
\end{tabular}

Quando observamos os dados acima, passamos a refletir sobre o que podem revelar acerca das competências e habilidades que a população estudantil brasileira demonstra possuir. Em quatorze descritores(2), os alunos brasileiros obtiveram resultado superior a 50\%, mas a maioria dos percentuais não ultrapassa a casa dos 60\%. Isso, no entanto, não colabora para o resultado geral, que poderia, sem dúvidas, ser melhor. Além disso, significa também que quase 50\% dos alunos avaliados não apresentaram desenvolvimento satisfatório das habilidades avaliadas. Para uma visualização mais abrangente, apresentamos o gráfico abaixo com esses percentuais. 


\section{GRÁFICO 1 - Índices dos resultados por habilidade no SAEB}

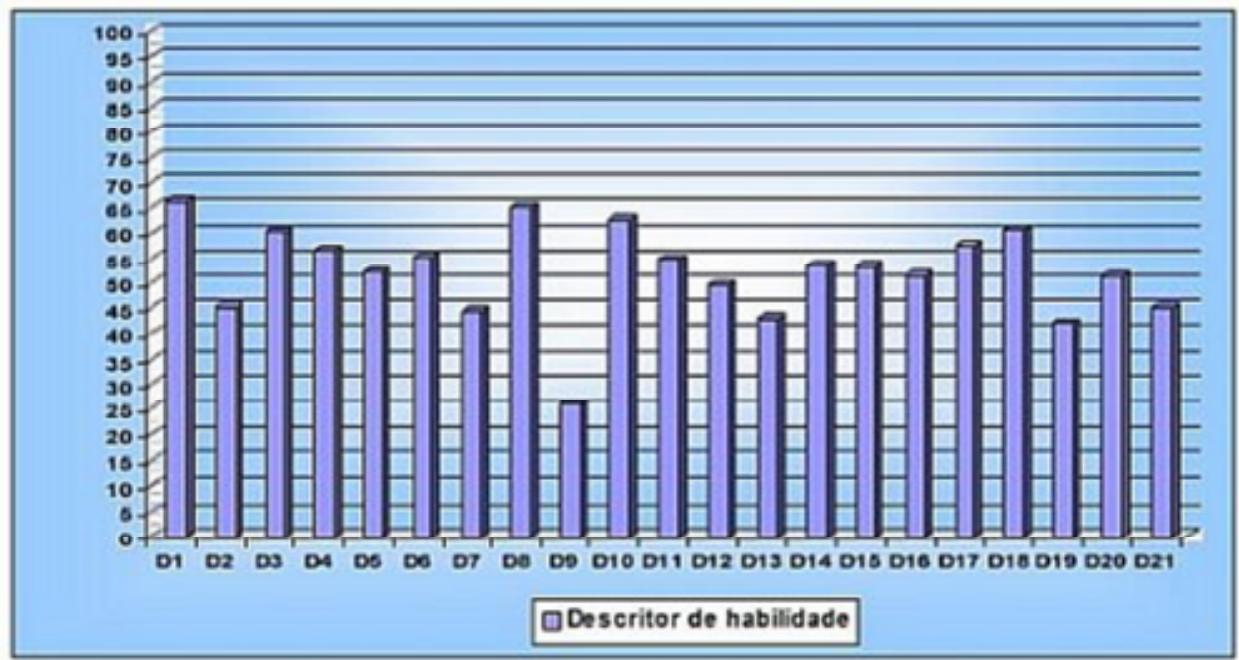

Pelos resultados acima, podemos reafirmar que os alunos submetidos ao SAEB apresentam um resultado entre $60 \%$ e $70 \%$ em apenas 5 das 21 habilidades: D1, D3, D8, D10, e D18.

Quando procuramos entender o que tais habilidades exigem, pensamos também nas implicações que a falta de domínio delas ocasiona. Quando o aluno é solicitado a localizar informações (D1), espera-se que ele, a partir das marcas textuais presentes na superfície do texto, responda às questões do tipo: o quê? quem? onde? como? quando? qual? para quê? Pretende-se, portanto, com esse descritor, verificar a capacidade de os alunos localizarem uma ou mais informações objetivas marcadas no texto. Não responder a questões de localização de informação significa que os alunos tiveram dificuldade na etapa da leitura referente à decodificação.

Em D3, inferir o sentido de uma palavra, é esperado que o leitor realize um raciocínio, a partir de informações já conhecidas, a fim de se chegar a informações novas, que não estejam explicitamente marcadas no texto por uma palavra ou expressão. Para construir o significado de uma palavra, não é necessário que se recorra sempre ao dicionário. Pode-se construílo a partir de marcas fonológicas, morfológicas, sintáticas e semânticas/pragmáticas. Se os alunos revelaram baixa proficiência nessa habilidade significa que tiveram dificuldade na construção de sentidos. Palavras e/ou expressões desconhecidas impuseram um grau de dificuldade que eles não conseguiram resolver pelo texto.

Em D8, estabelecer relação entre a tese e os argumentos oferecidos para sustentá-la, deve ser clara a noção de que o 
ponto de vista de quem escreve sobre determinado assunto é percebido por meio dos vários procedimentos utilizados na exposição de seus argumentos. Com esse descritor, espera-se que o leitor identifique os argumentos utilizados pelo autor na construção de um texto argumentativo. Essa tarefa exige do leitor, primeiramente, o reconhecimento do ponto (ou dos pontos) de vista que está sendo defendido e que o relacione aos argumentos usados para sustentá-lo. Se ele não percebe a estrutura argumentativa do texto, conseqüentemente terá sua compreensão comprometida.

Em D10, o aluno deve identificar o conflito gerador do enredo e os elementos que constroem a narrativa: personagens, enredo, foco narrativo, espaço. É preciso também que consiga identificar personagens, a relação entre elas e seus tipos (se são reais ou inventadas, se são seres animados ou inanimados), - enredo, o fato gerador do conflito, como se organizou e de que forma se resolveu, os tipos de enredo (aventura, de terror, suspense, ficção científica, de amor), o foco narrativo e o espaço. Um mau desempenho nesse descritor pode revelar pouca familiaridade com os textos e dificuldade com 0 grau de complexidade deles.

Em D18, a habilidade verificada é reconhecer o efeito de sentido decorrente da escolha de uma determinada palavra ou expressão. Esse descritor visa a verificar a capacidade de o leitor refletir sobre um dos aspectos relacionados à forma do texto e de perceber sutilezas da linguagem que interferem na construção de sentidos. A seleção lexical usada na construção do texto diz muito sobre as intenções comunicativas de quem o produziu. Quando não se consegue identificar o efeito de sentido provocado pelo uso de uma determinada expressão, entende-se que o leitor deixa de perceber a "intenção do autor" expressa por sua escolha lexical e que sua compreensão pode ficar comprometida.

Em outro grupo, o percentual foi entre $50 \%$ e $60 \%$ em 9 habilidades descritas em D4, D5, D6, D11, D14, D15, D16, D17 e D20.

Em D4, inferir uma informação em um texto, o desempenho dos alunos foi mediano (56\%). Nesse descritor, pretende-se verificar se os alunos são capazes de chegar às informações que não estão presentes claramente na base textual, mas que podem ser construídas por meio da realização de inferências, sugeridas pelas marcas que o texto sugerem. O leitor perspicaz é aquele que consegue ler o que está por trás das linhas (3). Ele deve, portanto, fazer inferências necessárias que contribuirão para a compreensão do texto. Quando não consegue realizá-las, o leitor não compreende o texto. Dessa forma, a leitura tende a dar-se apenas no nível da decodificação. 
O D5, desenvolver interpretação integrando o texto e o material gráfico, também se revelou num nível médio. Num texto, podem ser usados, além das palavras, elementos nãoverbais (fotos, desenhos, tabelas, gráficos, quadros), que visam a contribuir para a construção dos sentidos. Às vezes, uma imagem leva mais rapidamente à compreensão, porque o leitor consegue integrar imagem e texto. Quando essa tarefa não é cumprida, podemos dizer que o leitor tem dificuldade de lidar com os elementos não-verbais e, por conseqüência, não consegue estabelecer relações e atingir a interpretação desejada.

Em D6, a habilidade descrita é identificar o tema de um texto. o tema é o eixo sobre o qual o texto se estrutura. A percepção do tema responde a uma questão essencial para a leitura: o texto trata do quê?. Espera-se, com esse descritor, verificar a capacidade de o aluno construir o tema do texto a partir da interpretação que faz dos recursos utilizados pelo autor (como - uso de figuras de linguagem, de exemplos, de uma determinada organização argumentativa, dentre outros). Se o leitor não faz isso, significa que não percebe o texto como um todo, não consegue ainda perceber o nível mais abstrato de leitura pelo qual poderia construir o significado global ou a coerência temática (4).

Ainda entre 50\% e 60\%, encontramos D11, como a habilidade de estabelecer relação causa/conseqüência entre partes e elementos do texto. Entendemos como causa/conseqüência todas as relações entre elementos e fatos do texto, em que uma ação é resultado da outra. Para avaliar esse descritor, pode-se pedir ao leitor para reconhecer relações de causa e efeito, problema e solução, objetivo e ação, afirmação e comprovação/justificativa, motivo e comportamento, précondição e ação, dentre outras. Quando não estabelece essa relação, o leitor pode apresentar dificuldades na construção da coerência local e até mesmo da temática (5).

Em D14, o leitor deve distinguir um fato da opinião relativa a esse fato. Essa tarefa exige que o leitor perceba a diferença entre o que é fato narrado ou discutido no texto e o que é opinião sobre ele. Essa diferença pode ser bem marcada no texto, ou exigir do leitor que ele as perceba, integrando informações de diversas partes do texto e/ou inferindo-as. Em relação ao leitor que não realiza essa tarefa, podemos dizer que ele não consegue perceber as marcas textuais que revelam a posição do autor nem consegue realizar as inferências necessárias para o cumprimento desta tarefa. Isso compromete a produção de sentido, a compreensão.

Por D15, estabelecer relações lógico-discursivas presentes no texto, marcadas por conjunções, advérbios etc., o leitor deve 
identificar as relações (oposição, comparação, anterioridade, posterioridade etc.) presentes num texto, isto é, construir, a partir de conjunções, preposições e advérbios, dentre outros recursos lingüísticos, as relações entre frases, parágrafos ou partes maiores do texto. Quando não domina essa habilidade, podemos dizer que muito provavelmente o leitor não processa as relações expressas por essas conjunções e advérbios, dentre outros, comprometendo a construção do sentido global do texto.

Os resultados de D16 mostram que 51,6\% dos alunos foram capazes de perceber efeitos de ironia ou humor em textos variados. O humor e a ironia costumam ser comuns em vários gêneros de texto, mas nem sempre são facilmente compreendidos pelo leitor, pois, muitas vezes, exigem o conhecimento de situações que não são mencionadas no texto. A dificuldade apresentada nessa habilidade pode revelar a pouca familiaridade do aluno com a situação e o assunto tratados, ou seja, ausência de conhecimento prévio. A construção da coerência temática e da coerência local pode ser afetada caso - leitor tenha dificuldade de perceber efeitos de ironia ou humor no texto.

Em D17, temos um grupo de 57,4\% de leitores que conseguiu reconhecer o efeito de sentido decorrente do uso da pontuação $e$ de outras notações. Pela pontuação e por outros mecanismos de notação, como itálico, negrito, caixa alta, tamanho da fonte etc., efeitos de sentido podem ser criados no texto. O leitor deve perceber efeitos, e isso pode se tornar mais complexo à medida que são usados recursos não-convencionais e à proporção que os efeitos provocados por esses mecanismos gerem informações contrárias às expressas pelos recursos verbais. Quem não percebe os efeitos gerados pelo uso da pontuação pode fazer apenas uma leitura do literal, pode deixar de fora o humor, a dúvida e o suspense, dentre outros efeitos.

Entre 50\% e 60\%, encontra-se 0 D20, reconhecer diferentes formas de tratar uma informação na comparação de textos que tratam do mesmo tema, em função das condições em que eles foram produzidos e daquelas em que serão recebidos. As diferentes formas de se tratar uma mesma informação podem ser percebidas por meio da leitura dos títulos e das manchetes, da seleção lexical, do espaço dado à informação em um e em outro veículo, da natureza dos argumentos. O leitor que lê criticamente consegue identificar características que o levam a perceber o viés do texto. Se o leitor não consegue perceber que uma informação recebeu tratamento diferenciado num mesmo texto ou em diferentes textos, ele tem diminuída sua capacidade de crítica. Pode não ser capaz de perceber o efeito de manipulação que, muitas vezes, oculta-se por trás do tratamento dado à informação. 
Num patamar mais baixo do que o dos descritores acima, ou seja, com uma média de acertos variando entre 40\% a 50\%, encontramos um total de seis habilidades em D2, D7, D12, D13, D19 e D21.

Com relação à habilidade de D2, estabelecer relações entre partes de um texto, identificando repetições ou substituições que contribuem para a continuidade de um texto, o leitor deve ser capaz de (re)construir o caminho traçado pelo escritor e estabelecer as relações de continuidade marcadas no texto. Nesse sentido, o leitor deve ter habilidade de perceber como os referentes foram introduzidos e retomados no texto. Um leitor que revele pouca habilidade com o estabelecimento desse tipo de relação coesiva terá dificuldade em perceber a continuidade do texto, bem como de verificar sua progressão.

Em relação ao D7, identificar a tese de um texto, a média de acertos foi baixa $(44,5 \%)$. Entendemos que, em um texto argumentativo, seu produtor procura convencer ou persuadir alguém daquilo que ele, o produtor, acredita. Por isso defende uma tese, utilizando vários recursos lógicos e lingüísticos para atingir sua intenção persuasiva. O leitor que não tiver essa habilidade não consegue perceber as marcas textuais que revelam o ponto de vista e a intenção do autor bem com a sua posição, além de não ser capaz de perceber se há teses que, aparentemente, são concorrentes ou se apenas uma delas é defendida.

No descritor 12, identificar a finalidade de textos de diferentes gêneros, os alunos quase atingiram a média 50\%. Textos diferentes apresentam intenções comunicativas diferentes. Sendo assim, cabe ao leitor identificar a função, - objetivo de um determinado texto ou de uma parte dele. Reconhecer a finalidade do texto costuma ser uma tarefa simples e pode ser considerada fácil, ao passo que identificar um determinado efeito não muito explícito de uma parte do texto pode ser uma tarefa mais difícil. Quando não há domínio dessa habilidade, o leitor revela, às vezes, falta de conhecimento da diversidade textual e das funções dos gêneros.

Neste terceiro grupo, encontramos ainda a habilidade de D13, identificar marcas lingüisticas que evidenciam o locutor e o interlocutor de um texto. Quem tem essa habilidade deve ser capaz de identificar quem fala no texto e a quem o texto se destina, reconhecendo as marcas lingüisticas expressas. Muitos elementos do texto podem indicar o locutor e o interlocutor. Dentre eles, podemos citar a variante lingüística e o registro usado, o vocabulário, o uso de gírias e expressões, o suporte, os aspectos gráficos etc. A falta dessa habilidade acarreta o comprometimento da compreensão, visto que num texto a identificação dos interlocutores pode favorecer a produção de 
sentido, o delineamento das intenções do autor e as possíveis expectativas do leitor.

Em D19, encontramos a habilidade de reconhecer o efeito de sentido decorrente da exploração de recursos ortográficos e/ou morfossintáticos. O uso de recursos como diminutivos e/ou aumentativos, gradação, repetição de palavras, inversões na ordem das palavras, topicalizações e paralelismo sintático, dentre outros, precisam ser percebidos e compreendidos pelo leitor. Esse descritor visa, portanto, a verificar a capacidade do leitor de refletir sobre a forma do texto e, ainda, a verificar se ele consegue perceber as marcas utilizadas pelo autor na construção de sentidos. O grau de dificuldade desse descritor advém da falta de percepção de que no texto são utilizados recursos específicos para causar efeitos. A falta dessa habilidade leva o leitor a não compartilhar o jogo interativo que o autor quer instaurar por meio do texto.

O D21, que descreve a habilidade de reconhecer posições distintas entre duas ou mais opiniões relativas ao mesmo fato ou ao mesmo tema, atingiu a porcentagem de 45\%. Nesse descritor, espera-se que o leitor possa identificar, em um mesmo texto ou em textos diferentes, pontos de vista semelhantes ou contraditórios defendidos sobre determinado tema. A dificuldade nesse descritor situa-se no fato de, às vezes, não haver marcas bastante claras no texto que evidenciem as posições que estão sendo assumidas. A ausência dessa habilidade pode revelar que o leitor apresenta dificuldades em relacionar diferentes partes do texto, bem como de fazer inferência, ou de perceber sutilezas no texto; sua leitura provavelmente está ainda no horizonte mínimo da paráfrase (6). O leitor não é capaz de perceber que um mesmo fato pode gerar opiniões divergentes. Não estabelece distinção entre os textos que lê. Pode, portanto, ser um leitor pouco crítico.

$\mathrm{Na}$ última categoria, encontra-se o mais baixo índice da prova SAEB: 26\% em D9, diferenciar as partes principais das secundárias em um texto. Assim como é importante que o leitor seja capaz de identificar o assunto principal de um texto, é necessário que ele reconheça as partes em que ele se divide, como se organiza e as relações entre a idéia principal e essas partes. O grau de dificuldade dessa tarefa aumenta proporcionalmente ao grau de explicitação das relações marcadas no texto. Quando não apresenta tal habilidade, a compreensão e a percepção da macroestrutura textual ficam comprometidas. Isso significa que o leitor não foi capaz de estabelecer correlações, não foi capaz de distinguir num texto - essencial do acessório. Uma complicação inerente a essa habilidade é o fato de que o que pode ser relevante para um 
leitor num determinado texto, pode não o ser para outro, isso só pode ser definido pelos objetivos da leitura.

Vimos que cada habilidade listada possui seu grau de importância na construção do sentido e que a falta de domínio de cada uma pode comprometer na compreensão do texto. Foi também possível perceber que as habilidades de leitura estão, de certa forma, interligadas e, em conjunto, contribuem para uma produção eficaz de sentido.

\section{Considerações finais}

- desempenho revelado pelos alunos brasileiros deixa a desejar, visto que, em habilidades básicas como a localização de informações (D1), o índice de acerto fica em torno dos 60\%. Em nenhuma das habilidades avaliadas pelo SAEB, O nível de acertos atingiu o percentual de 70\%. Outras habilidades que exigem operações mentais mais elaboradas e que são importantes para uma leitura proficiente, como a correlação de informações (D2), a percepção de efeitos de sentido provocados pelo uso de recursos diversos (19), dentre outras, ficaram abaixo de 50\%. Isso nos leva a pensar que, para uma leitura eficiente, os alunos brasileiros ainda têm muito a desenvolver. Os dados apontam para a necessidade urgente de medidas de intervenção e para uma reformulação das práticas escolares. Tais práticas devem propiciar o desenvolvimento das diversas habilidades, para que a população brasileira, após pelo menos oito anos de escolarização, apresente um desempenho melhor na leitura.

Todas as habilidades de leitura analisadas são desejáveis num leitor proficiente e correspondem a operações cognitivas elaboradas. Como conseqüência do não-desenvolvimento delas teremos leitores pouco ativos, que não conseguem agir sobre o texto, ficando sua leitura na superfície textual. Aos alunos, é subtraída a oportunidade de treinar o raciocínio, o pensamento crítico e as habilidades argumentativas (7).

Os resultados oficiais divulgados do SAEB/2001 revelam uma possível resposta à pergunta "Por que eles não lêem?". Não lêem, porque não são desenvolvidas estratégias que contemplem múltiplas habilidades de leitura na escola. Ou não lêem porque não apresentam essas habilidades desenvolvidas satisfatoriamente.

\section{Abstract}

This paper has the objective to present a reflection about the principal reading skills verified in systemic evaluation e about the implications of non developed of these skills.

Key-words: school, reading skills and evaluation. 


\section{Notas}

(1) Este artigo reproduz parcialmente teoria e análise de dados da dissertação de mestrado apresentada ao Programa de Pós-Graduação em Estudos Lingüísticos da Faculdade de Letras da Universidade Federal de Minas Gerais "O que provam as provas: habilidades de leitura em avaliações sistêmicas X habilidades de leitura em livro didático", de Souza (2005), sob as orientações das professoras Carla Coscarelli e Delaine Cafiero.

(2) Descritor pode ser entendido como o detalhamento de uma competência. O tipo de habilidade cognitiva que o estudante deve revelar é explicitado por meio de um descritor.

(3) SCOTT, 1985.

(4) COSCARELLI, 1999.

(5) CLARK \& CLARK, 1977.

(6) MARCUSCHI, 1996.

(7) MARCUSCHI, 1996.

\section{Bibliografia}

CLARK, H. H. e CLARK, E. V. Psychology and language. New York: Hardcourt Brace Jovanovich, 1977.

COSCARELLI, Carla V. Leitura em ambiente Multimídia e a Produção de Inferências. Tese (Doutorado em Lingüística) Faculdade de Letras, UFMG, Belo Horizonte, 1999.

MARCUSCHI, L. A. Compreensão de texto: algumas reflexões. In: Ângela Dionísio \& Maria Auxiliadora Bezerra. (org.) O livro didático de português. Rio de Janeiro: Lucerna.p. 48-61. 2a ed. 2003a.

MARCUSCHI, L. A. Descritores para o ensino de língua portuguesa: pertinência e paradoxo. I Reunião Regional - SBPC - ABRALIN. Campina Grande, 7 a 13 de novembro de 2003b.

PISA. Programa de Avaliação Internacional de Estudantes. Relatório. Inep, 2000 .

SAEB. Sistema Nacional de Avaliação da Educação Básica. Relatório Saeb 2001. Brasília: MEC, 2003.

SCOTT, Michael. Lendo nas Entrelinhas. Ilha do Desterro. Florianópolis, n.13. 1985. P. 101-123.

SoUZA, Cláudia M. O que provam as provas: habilidades de leitura em avaliações sistêmicas $X$ habilidades de leitura em livro didático. Dissertação (Mestrado em Lingüística) Programa de Pós-Graduação em Estudos Lingüísticos da Faculdade de Letras da UFMG, Belo Horizonte, 2005. 